\title{
"DAS CIDADES SE DEVERIA TOMBAR A ATMOSFERA"; UM OLHAR SOBRE O COMPLEXO CULTURAL DA MARINHA E A ECONOMIA CRIATIVA NO RIO DE JANEIRO
}

CITIES ATMOSPHERE SHOULD BE HERITAGE: A LOOK AT THE CULTURAL

COMPLEX OF THE NAVY AND THE CREATIVE ECONOMY IN RIO DE JANEIRO

\section{Lucia Santa Cruz}

Doutora em Comunicação e Cultura pela Universidade Federal do Rio de Janeiro (Rio de Janeiro/Brasil). Professora da Escola Superior de Propaganda e Marketing (Rio de Janeiro/Brasil).

E-mail: lucia.santacruz@espm.br

\section{Lorena Fraga Costa Moulin}

Mestra em Gestão da Economia Criativa pela Escola Superior de Propaganda e Marketing (Rio de Janeiro/Brasil). Assessora de Comunicação na Marinha do Brasil (Rio de Janeiro/Brasil).

E-mail: Iorenafragacosta@gmail.com 


\section{Brazilian

\section{RESUMO}

Este artigo objetiva identificar como o Complexo Cultural da Marinha, no Centro do Rio de Janeiro, estimula o desenvolvimento da Economia Criativa carioca. Utilizou-se coleta de dados por pesquisa bibliográfica, pesquisa documental e uma entrevista em profundidade, semi-aberta, com roteiro feito a partir de questões semiestruturadas. Realizou-se ainda análise de conteúdo, resultando em três abordagens categorizadas. Analisouse o cenário de reestruturação da região do entorno do Complexo desde a criação do Corredor Cultural; a participação dos militares na economia criativa e a interação da Força Armada com a sociedade civil por meio de equipamentos culturais. Concluiu-se que o Complexo auxilia na manutenção de cidadãos naquela região, por meio de seus equipamentos culturais. Observou-se ainda que o Complexo Cultural da Marinha preserva, valoriza e difunde o patrimônio histórico tanto da Força Armada quanto do Brasil, estímulo esse fornecido à Economia Criativa na cidade carioca, e, por consequência, ao desenvolvimento da região.

Palavras-chave: Economia Criativa. Patrimônio Cultural. Complexo Cultural da Marinha. Corredor Cultural. Memória Coletiva.

\section{ABSTRACT}

This paper aims to identify how the Cultural Complex of the Brazilian Navy, in downtown Rio de Janeiro, stimulates the development of the Rio de Janeiro Creative Economy. Data collection was performed through bibliographic research, documentary research, and an in-depth, semi-open interview, with script made from semi-structured questions. Content analysis was also performed, resulting in three categorized approaches. The restructuring scenario of the region surrounding the Complex was analyzed since the creation of the Cultural Corridor; the participation of the military in the creative economy and the interaction of the military with civil society through cultural facilities. It was concluded that the Complex assists in the maintenance of citizens in that region through its cultural facilities. It was also observed that the Cultural Complex of the Navy preserves, enhances and disseminates the historical heritage of both the Armed Forces and Brazil, a stimulus provided to the Creative Economy in the city of Rio de Janeiro, and, consequently, to the development of the region.

Keywords: Creative Economy. Cultural Heritage. Navy Cultural Complex. Cultural Corridor. Collective Memory. 


\section{Brazilian

\section{INTRODUÇão}

Localizado no Corredor Cultural do centro da cidade do Rio de Janeiro, na região conhecida como Boulevard Olímpico, o Complexo Cultural da Marinha do Brasil é formado por um circuito de museus, passeios e exposições, entre eles o Espaço Cultural, a Ilha Fiscal, o Museu Naval e, atualmente, trabalha para a construção de um novo equipamento cultural no local: o Museu Marítimo (MARINHA DO BRASIL, 2019). Após as obras de reestruturação da região portuária, a demolição do viaduto da Perimetral e a construção da Orla Prefeito Luiz Paulo Conde, as opções culturais da Marinha ficaram mais visíveis à população, já que a região, outrora de difícil acesso por conta do elevado fluxo de veículos em dias úteis e por ser um local deserto nos fins de semana, agora se constitui num atrativo circuito de entretenimento local.

Essas obras, em pleno século XXI, foram resultados de um dos maiores projetos de requalificação urbana da cidade, o chamado Porto Maravilha, idealizado para permitir reconexões. Uma delas foi a reaproximação da população com a paisagem marítima da região, conforme retrata publicação da Unesco (RIBEIRO, 2016, p. 52) que descreve o Rio como patrimônio mundial: "Com a vista para o mar fechada por um grande viaduto construído nos anos 1960, sua implosão e seu desmanche marcam a volta da valorização da relação dessa parte da cidade com o mar [...]". Relação essa que aconteceu em determinados trechos da história e demonstra indícios de resgate, incluindo reforços via equipamentos culturais da Marinha na região, já que se trata da identidade carioca, e porque não dizer nacional, batizadas pelas águas da baía da Guanabara há séculos:

Até meados do século XIX, a relação da cidade com o mar se dava quase que unicamente por meio de sua função portuária, dos banhos de mar indicados por médicos, da contemplação ou como local de deposição dos dejetos; porém, aos poucos, essa relação começou a se transformar. Já no final daquele século, foram criados vários clubes de regatas, e as competições nas águas da baía se transformaram em importantes acontecimentos. Esses clubes de regatas deram origem aos principais clubes de futebol da cidade (Flamengo, Vasco da Gama, Fluminense e Botafogo), o esporte que se consolidou como uma das identidades do país. (RIBEIRO, 2016, p. 52).

Além do importante estímulo à conexão da população carioca com o mar, a revitalização da zona portuária foi concebida, entre outros motivos, para resolver um problema que o Rio carregava desde os anos 1970: o esvaziamento do centro da cidade. "O Porto Maravilha tem como objetivo trazer novamente a população para aquela área, pela instalação de novos equipamentos culturais, como museus, pela construção de bulevares para pedestres [...]" (RIBEIRO, 2016, p. 52). Tal programa sinaliza 


\section{Brazilian

o reconhecimento por parte de governantes do papel fundamental de iniciativas abarcadas no guardachuva dos conceitos teóricos do campo da Economia Criativa e da formação de cidades com esse viés, tendo como impulsionadores espaços culturais, a fim de promover reestruturação urbana (REIS, 2011).

A ideia segue o direcionamento da Unesco (2019) ao afirmar que "o turismo cultural sustentável, as indústrias culturais e criativas, bem como a revitalização urbana baseada em seu patrimônio são poderosos subsetores econômicos que geram empregos verdes, estimulam o desenvolvimento local e incentivam a criatividade".

O fenômeno de esvaziamento dos centros urbanos foi observado em diversas cidades pelos idos de 1970, não apenas na carioca, mas em outros locais pelo mundo. No caso do Rio, dois fatores principais contribuíram para esse fenômeno.

Em primeiro lugar, a própria legislação municipal que proibiu a construção de novas habitações no Centro, para estimular a ocupação e o crescimento da cidade em direção aos novos bairros [...] e a transferência da capital do Rio de Janeiro para Brasília, que reduz a permanência de pessoas, das funções institucionais, de novos investimentos e ainda de significado (FONSECA, 2009, p. 37).

Outro diferencial do Rio é a peculiaridade cultural em relação às opções de lazer e entretenimento. Por ser uma cidade tropical, com belezas naturais indiscutiveis, os cariocas culturalmente fazem atividades ao ar livre, estão nas ruas, gostam de sair, além de receber turistas que buscam justamente essa atmosfera. Virtudes essas reconhecidas mundialmente. Não é à toa que o Rio de Janeiro se tornou a primeira grande cidade do mundo inscrita na Lista da Unesco como Paisagem Cultural do Patrimônio Mundial (UNESCO, 2019). Vislumbra-se um público latente, que descobre uma nova forma de se relacionar com a região central da cidade e a reboque encontra o Complexo Cultural da MB, com diversos equipamentos culturais ao ar livre, os quais serão apresentados mais à frente.

Diante disso, esse artigo objetiva identificar como o Complexo Cultural da Marinha no Rio de Janeiro estimula o desenvolvimento da Economia Criativa na cidade carioca. Ele faz parte da pesquisa desenvolvida no Mestrado Profissional em Gestão da Economia Criativa, da Escola Superior de Propaganda e Marketing (ESPM), no Rio de Janeiro.

O argumento central deste trabalho é que o Complexo Cultural da Marinha, entre os pressupostos da Economia Criativa, configura-se como ator de promoção da reestruturação do espaço onde está localizado, proporciona a valorização do patrimônio histórico, cultural e o resgate da memória da região, além de contribuir com a interação da Força Armada com a sociedade. 


\section{Brazilian \\ Creative Industries}

Para a pesquisa exploratória que embasa este artigo, foi utilizado o método qualitativo, de acordo com o objetivo descrito. A escolha do tipo de pesquisa se deve ao fato de que é necessário criar maior familiaridade com o tema escolhido, o qual ainda é pouco explorado, com o intuito de torná-lo mais explícito (GIL, 2002), já que os conceitos de Economia Criativa são recentes e permeados de discussões no campo teórico. A coleta de dados foi feita por pesquisa bibliográfica, pesquisa documental e uma entrevista em profundidade, semiaberta, com o gerente de visitação do Complexo Cultural da Marinha no RJ, Capitão de Fragata RM1 (T) José Marques da Silva Filho, com roteiro feito a partir de questões semiestruturadas, e realizada análise de conteúdo dos conceitos trazidos pelos teóricos e pelos dados a partir de livros, artigos científicos, revistas, matérias jornalísticas e conteúdos institucionais do site da Marinha para traçar o marco teórico do conceito supracitado. Na análise de conteúdo, a referência seguida foi Bardin (1979), pelo rigor metodológico perseguido no intuito de analisar os documentos, as bibliografias e entrevista.

O marco teórico de referência no campo da Economia Criativa foi a partir de Charles Landry em nível internacional e Ana Reis, em nível nacional. John Howkins é citado neste trabalho, pois é o grande impulsionador do termo "economia criativa", apesar de fazê-lo com o foco em "indústrias criativas" ligadas à geração de direitos autorais e patentes, temática que não foi abordada nesta pesquisa.

Este trabalho destaca a discussão do conceito na perspectiva de "cidades criativas", de Charles Landry (1998; 2000), autor de The creative city (A cidade criativa) e The creative city: a toolkit for urban innovators (A cidade criativa: um kit de ferramentas para os inovadores urbanos), quando destaca a singularidade dos espaços, que ganha força por meio de suas manifestações culturais e sua identidade, além de trazer o papel das cidades, e com elas seus bens preciosos, incluindo aía cultura, como motor de desenvolvimento.

Reis (2012, p. 220) corrobora a idéia de Landry (2000) ao trazer à discussão as nuances da cidade criativa. "A cultura, na cidade criativa, é sua digital, é justamente o que the dá singularidade, gerando impactos econômicos, benefícios sociais (autoestima, coesão e engajamento) e favorecendo a construção de um ambiente criativo".

A seguir, analisaremos o cenário de reestruturação da região do entorno do Complexo desde a criação do Corredor Cultural. Na seção seguinte, analisaremos a participação dos militares na economia criativa por meio do Complexo Cultural. Antes de desenvolver as considerações finais, identificaremos a interação da Força Armada com a sociedade civil. 


\section{Brazilian

\section{DESENVOLVIMENTO}

Antes de partir para a categorização das três abordagens resultantes da pesquisa, identifica-se a necessidade de uma contextualização, bem como uma discussão teórica no campo da Economia Criativa, além da evolução do conceito de patrimônio, para então permitir o avanço ao objeto de estudo.

\subsection{DISCUSSÃO TEÓRICA}

\subsubsection{Economia criativa}

A criatividade não é um termo novo nem desconhecido, assim como o conceito de economia. A novidade está na relação entre elas e como elas se combinam para gerar valor e riqueza. Na economia criativa, o motor principal fica a cargo do talento humano, da criatividade, conforme defende Howkins (2013, p. 105), pois "é a matéria-prima mais importante e o produto econômico mais valioso".

A origem do conceito de economia criativa é recente. Foi há 25 anos, especificamente em 1994, na Austrália, com o termo "indústrias criativas", orientado por um projeto de governo daquele país, intitulado "Creative Nation". O governo australiano propunha a busca da identidade cultural australiana com a aplicação de verbas, por meio de um fundo de investimento, nas indústrias cinematográfica, teatral e artística. Esse projeto defendia a relevância do trabalho criativo, sua contribuiç̧ão para a economia do país, e o papel das tecnologias como aliadas da política cultural (REIS, 2008).

Posteriormente, na Inglaterra, no ano de 1997, o termo foi realmente desenvolvido no âmbito de uma abordagem político-econômica e sua relação com o desenvolvimento, tornando-se referência para outros países, conforme retrata Reis (2008). O governo do então primeiro ministro Tony Blair, diante da crescente competição econômica global, motivou a formação de uma força-tarefa multissetorial encarregada de analisar as contas nacionais do país, as tendências de mercado e as vantagens competitivas nacionais.

Reis (2006, p. 198) também destaca o diferencial dessa nova economia, bem como sua finalidade: "a economia criativa tem despertado atenção por seu potencial de união da economia e da cultura em prol do desenvolvimento sustentável".

Nesse caminho, não se pode falar de Economia Criativa sem apresentar a abordagem sobre cultura e atividades culturais. David Throsby (2001) ressalta a cultura nos temas relacionados às indústrias criativas. Ele denomina atividades culturais aquelas que reúnem criatividade, certo grau de propriedade intelectual e transmitem valor simbólico. E ainda, a relação entre cultura e economia na geração de desenvolvimento.

Os economistas têm dedicado pouca atenção ao papel da cultura no desenvolvimento econômico, seja ao contextualizar o processo de crescimento no mundo em 


\title{
Brazilian

\begin{abstract}
desenvolvimento ou ao influir mais diretamente nos resultados econômicos dos países desenvolvidos. Há provas de que esses paradigmas tradicionais estão mudando. Em anos recentes despertou-se interesse considerável pela noção de que, longe de ser periférica ao desenvolvimento econômico, a cultura é inextricável e central a ele, oferecendo tanto o contexto no qual o progresso econômico ocorre, quanto o próprio objeto de desenvolvimento, quando vista sob a perspectiva das necessidades individuais (THROSBY, 2001, p. 164).
\end{abstract}

Segundo a Unesco, atividades do setor cultural representam 6,1\% da economia mundial, geram uma renda anual de US\$2,25 bilhões e quase 30 milhões de empregos no mundo.

No entanto, segundo o órgão, até recentemente a cultura não estava incluída na equação de desenvolvimento. Por isso a Unesco (2019) tem defendido essa ideia ao demonstrar que "a revitalização urbana baseada em seu patrimônio são poderosos subsetores econômicos que geram empregos verdes, estimulam o desenvolvimento local e incentivam a criatividade [...]". Com isso, o órgão recomenda a inserção da política cultural como fomentadora do desenvolvimento, "de forma a garantir que a cultura ocupe um lugar legítimo nas estratégias e nos processos de desenvolvimento".

Apesar da globalização - que força a qualquer custo equalizar mercadorias principalmente devido à quase extinção da barreira tempo-espaço de McLuhan (1964) - a cidade constitui-se como núcleo da aldeia global, onde está guardada a riqueza das nações, parafraseando a obra de Adam Smith (1776).

O conceito de cidade criativa foi considerado inicialmente por Landry (2011) como um lugar onde a imaginação definia os traços e o espírito da cidade.

\footnotetext{
Para aproveitar ao máximo a criatividade [de uma cidade], é preciso considerar seus recursos de modo mais amplo e nos basear na história dos lugares e na evolução de sua cultura. Levar a cultura em consideração nos ajuda a entender de onde um lugar vem, por que ele está como está e como pode criar seu futuro, por meio de seu potencial. Esses recursos culturais são a matéria-prima da cidade e sua base de valores; seus ativos, substituindo o carvão, o aço ou o ouro. Criatividade é o método para explorar esses recursos e ajudá-los a crescer (LANDRY, 2011, p. 15).
}

Na nova economia, a um passo de cada morador, e por que não dizer, em cada um, habita a criatividade, moeda mais valiosa do século XXI, o que faz desse humano o capital mais precioso da era corrente. "A economia da criatividade difere da economia convencional, já que o individual assume um papel central". (HOLKWINS, 2013, p. 149).

O conceito da Economia Criativa é caracterizado, por fim, como uma saída ao clamor social, muito além da lacuna econômica, por uma maneira diferente de viver, de trabalhar, de se relacionar como o 


\section{Brazilian

outro e com o meio ambiente. A rede da tecnologia perpassa as correntes elétricas e os códigos binários e alcança as pessoas, uma a uma, na sua identidade, ao mesmo tempo em que todos juntos, numa rede de colaboração. Reis (2008) apresenta uma explanação desse novo paradigma, que traz oportunidades vislumbradas diante desse ciclo, tendo a cultura como protagonista.

"A economia criativa não é apenas um apanhado de setores embalados em uma nova categoria, mas o emblema de um novo ciclo econômico, que surge como resposta a problemas globais renitentes. [...] Nesse novo paradigma, que traz a cultura em sua essência e a tecnologia como veículo propulsor, a organização dos mercados em redes, as parcerias entre os agentes sociais e econômicos, a prevalência de aspectos intangiveis da produção, o uso das novas tecnologias para a produção, distribuição e/ ou acesso aos bens e serviços e a unicidade da produção, fortemente ancorada na singularidade, são traços característicos desse modelo que tem como pressuposto de sustentabilidade a melhoria do bem-estar e a inclusão socioeconômica (REIS, 2008, p. 47).

O conceito de Economia criativa tem origem recente. Os órgãos internacionais ligados à ONU recentemente chegaram numa definição do que seria essa abordagem. Ela encontra-se no limiar entre as forças econômicas e o patrimônio de uma nação (MADEIRA, 2014), e tem como base e alvo um patrimônio precioso - a cultura.

Nesse aspecto, Landry $(2000$, p. 7) reverencia a singularidade dos espaços, trazendo como vitamina para fortalecer essa dinâmica a criação de identidade e manifestações culturais: "Cultura e criatividade estão interligadas. Cultura é a panóplia de recursos que mostram que um lugar é único e distinto [...]".

\subsubsection{0 conceito de patrimônio}

A noção de patrimônio surge no direito romano para designar o conjunto de bens herdados (DESVALLÉS; MAIRESSE, 2013). Dela derivam o patrimônio genético, que designa as características hereditárias de um ser vivo; e patrimônio cultural, que, a partir da Revolução Francesa, teria passado a indicar o conjunto de bens imóveis, "confundindo-se geralmente com a noção de monumentos históricos" (DESVALLÉS; MAIRESSE, 2013, p. 73).

No século XX, a noção de patrimônio ampliou-se, englobando, progressivamente, o conjunto de testemunhos materiais do homem e do seu meio, o que representou incluir o patrimônio folclórico, o patrimônio científico e, mais recentemente, o patrimônio industrial (DESVALLÉS; MAIRESSE, 2013). É também no final do século passado que o patrimônio imaterial passa a ser considerado como um bem cultural. 


\title{
Brazilian \\ Creative Industries
}

No Brasil, é com o Decreto 3.551, de 4 de agosto de 2000, que instituiu o inventário e o registro do denominado "patrimônio cultural imaterial ou intangivel", que se estabelece uma nova concepção para a proteção cultural.

\begin{abstract}
Se durante décadas predominou um tipo de atuação preservacionista, voltada prioritariamente para o tombamento dos chamados bens de pedra e cal - igrejas, fortes, pontes, chafarizes, prédios e conjuntos urbanos representativos de estilos arquitetônicos específicos - , o referido decreto pôs em cena uma antiga preocupação de alguns intelectuais brasileiros, entre os quais se destacou Mário de Andrade, qual seja, a de valorizar o tema do intangivel, contribuindo social e politicamente para a construção de um acervo amplo e diversificado de expressões culturais, em diferentes áreas: línguas, festas, rituais, danças, lendas, mitos, músicas, saberes, técnicas e fazeres diversificados (ABREU; CHAGAS, 2009, p. 13).
\end{abstract}

No embalo de Mario de Andrade, Gonçalves (2002) perfaz, com categoria, uma interligação entre "patrimônio cultural" e "romance" ao descrever que as narrativas com o termo "patrimônios culturais" nasceram com o romance e com a formação dos Estados nacionais, que utilizaram esses discursos para construir memórias, tradições e identidades.

Assim como no romance, o que está em foco nas narrativas de patrimônio é a experiência de formação de uma determinada subjetividade coletiva, a "nação", como coletividade individualizada e, a exemplo dos indivíduos, dotada de memória, caráter, identidade etc. De certo modo, as narrativas de patrimônio são romances nacionais. (GONÇALVES, 2002, p. 116).

Rodrigo Melo Franco de Andrade, fundador e durante 30 anos diretor da instituição federal de preservação do patrimônio histórico e artístico nacional, o então Sphan, comenta em seus textos, conforme descreve Fonseca (2002, p. 118), que "a 'tradição' é o que faz a mediação entre o passado e o presente da nação. 0 conjunto de bens que são classificados como 'patrimônio' representa precisamente essa 'tradição', vinculando os brasileiros de ontem aos de hoje".

O passado e a tradição foram cultuados nos anos de 1930 por Manuel Bandeira, escritor consagrado do País e que também foi um colaborador do Sphan, ao afirmar que para os brasileiros, "o que tem força de nos comover são justamente esses sobradões pesados, essas frontarias barrocas, onde alguma coisa de nosso começou a se fixar. A desgraça foi que esse fio de tradição se tivesse partido" (BANDEIRA, 1938, p. 42 apud GONÇALVES, 2002, p. 119). Gonçalves (2002, p. 119) arrisca explicar o sentimento do escritor 


\section{Brazilian \\ Creative Industries}

ao destacar que "essa modalidade de narrativa do patrimônio vai, precisamente, tentar reconstituir esse fio partido da tradição".

Já na década de 1970, as narrativas de patrimônios culturais referentes ao passado e à tradição perdem espaço, ao mesmo tempo em que vai sendo utilizado cada vez mais o termo bens culturais (GONÇALVES, 2002), com destaque para a individualidade da experiência e a valorização do presente e auxiliadores para um futuro melhor, com foco em desenvolvimento. Interessante esse recorte, pois observa-se que no Brasil de meados do século XX já se discutia o que os teóricos americanos e europeus trariam nas literaturas de anos correlatos sobre cidade e desenvolvimento, atrelando o termo "cidades criativas", de Landry (1998).

"O patrimônio cultural é de fundamental importância para a memória, a identidade e a criatividade dos povos e a riqueza das culturas." (UNESCO, 2019). Bokova (2012) reforça o argumento descrito no site do órgão das Nações Unidas, reiterando o papel da valorização do patrimônio cultural no desenvolvimento.

Cultura é, por excelência, um recurso renovável, constituindo-se assim numa importante dimensão do desenvolvimento sustentável. É uma força que promove inclusão social e mobilização coletiva. A experiência tem provado que o reconhecimento da importância do patrimônio cultural na criação e implementação de políticas de desenvolvimento é um fator que estimula a participação ativa das comunidades e potencializa a eficácia de programas a longo prazo (BOKOVA, 2012, p. 5).

A Constituição Federal de 1988, em seu Artigo 216, conceitua patrimônio cultural como "bens de natureza material e imaterial, tomados individualmente ou em conjunto, portadores de referência à identidade, à ação, à memória dos diferentes grupos formadores da sociedade brasileira". (BRASIL, 1988).

O sociólogo francês Maurice Halbwachs (1990), ao analisar a memória coletiva, enfatizou a força dos diferentes pontos de referência que estruturam a memória individual, operando na construção das identidades, no sentimento de pertencimento e na construção dos saberes. Para ele, as memórias individuais devem ser entendidas como um ponto de vista sobre a memória coletiva, que se torna um suporte confiável ao qual recorremos para lembrar de um determinado fato. A partir desta perspectiva, Pierre Nora (1993) cunhou a expressão "lugares de memória", para designar lugares físicos ou imateriais nos quais uma sociedade deposita suas lembranças, ao mesmo tempo em que circunscreve o que deve ser lembrado por aquele grupo. Nesse sentido, Oliveira (2002 apud ROLIM, 2013, p. 4) destaca que

A memória fica enraizada no concreto, no espaço, no gesto, na imagem, no objeto, e desse modo é possivel afirmar que o patrimônio histórico, seja ele material ou imaterial, é sustentáculo de memórias, e como tal incorpora fragmentos e sentimentos 


\section{Brazilian

experienciados socialmente pelo indivíduo e pela coletividade em espaços e tempos determinados (OLIVEIRA, 2002 apud ROLIM, 2013, p. 4).

Uma concepção semelhante à defendida por Hartog (2006), que destaca a premência do homem do presente de preservar e proteger a memória, patrimonializando a história, especialmente a partir dos anos 1960. "O patrimônio é uma maneira de viver as rupturas, de reconhecê-las e reduzi-las, referindo-se a elas, elegendo-as, produzindo semióforos ${ }^{1}$ (HARTOG, 2006, p. 272).

Diante do exposto, pode-se afirmar que por meio dos equipamentos do Complexo Cultural é possível resgatar a memória e a identidade e fomentar a consolidação de uma mentalidade marítima.

A Unesco defende o poder da cultura de transformar as sociedades. Ao relacionar cultura e desenvolvimento sustentável, recomendou a inserção da política cultural como fomentadora do desenvolvimento.

\footnotetext{
Tanto o patrimônio cultural quanto a criatividade lançam suas bases para a construção de sociedades do conhecimento vibrantes, inovadoras e prósperas. O patrimônio cultural constitui uma fonte de identidade e coesão para as comunidades conturbadas por mudanças desorientadoras e instabilidade econômica. A criatividade contribui para a construção de sociedades abertas, inclusivas e pluralistas (UNESCO, 2019).
}

O Relatório de 2018 da Conferência das Nações Unidas a respeito de Comércio e Desenvolvimento (UNCTAD) sobre perspectivas da Economia Criativa a partir de dados de 2002 a 2015 reconhece o potencial do Brasil no setor criativo: "[...] 0 país é hoje um dos maiores mercados culturais do mundo [...]" (UNCTAD, 2018, p. 98, tradução da autora).

O mercado mundial de bens criativos, segundo o Relatório, mais que dobrou, passando de $U \$$ 208 bilhões em 2002 para US \$ 509 bilhões em 2015. No caso do Brasil, o relatório mostra que as exportações dos bens criativos brasileiros somaram $U \$$ 923,4 milhões em 2014 e o setor empregou mais de 11 milhões de pessoas (com cerca de 2 milhões de novos empregos).

O relatório demonstra não apenas o crescimento significativo da economia criativa nos últimos anos, mas retrata a contribuição valiosa para a conquista de metas de desenvolvimento sustentável.

Segundo a Secretária-Geral da Unctad, Mukhisa Kituyi (2018, p. 3, tradução da autora), "a economia criativa tem valor comercial e cultural. Reconhecimento desse valor dual levou governos de todo o mundo

\footnotetext{
${ }^{1}$ Um tipo de símbolo cujo significado altera a realidade no momento em que é compreendido.
} 


\section{Brazilian \\ Creative Industries}

a expandir e desenvolver suas economias criativas como parte de estratégias de diversificação econômica e esforços para estimular crescimento econômico, prosperidade e bem-estar".

Os aparelhos culturais da área do Porto Maravilha, como o Museu do Amanhã e o MAR (Museu de Arte do Rio) foram concebidos para serem "âncoras culturais do que seria o 'resgate' da região portuária" (SANTA CRUZ, 2017, p. 189). Nessa "maré" está o Complexo Cultural da Marinha, com destaque para o futuro Museu Marítimo, para o qual, diante do exposto, é nítido o papel dos equipamentos culturais nele compreendidos no desenvolvimento da economia criativa, na perspectiva da valorização do patrimônio histórico e no resgate da memória da região.

\subsection{RESULTADOS, ANÁLISE E DISCUSSÃO}

O resultado da pesquisa culminou em três abordagens categorizadas da seguinte forma:

\subsection{1 "Das cidades se deveria tombar a atmosfera": reestruturação da região com espaços criativos}

O clima e a alma cultural do Rio de Janeiro - inserido na lista da Unesco (2019) como patrimônio mundial - já haviam sido poetizados pelo escritor Mário de Andrade, quando descreveu a abrangência do patrimônio e o potencial que uma cidade pode ter ao valorizar suas riquezas intangiveis: "Das cidades se deveria tombar a atmosfera" (PINHEIRO, 2002a, p. 147), numa referência ao que deveria ser preservado e que perpassa o material.

O centro do Rio de Janeiro retrata tanto a história da cidade quanto a do país, por ter sido sede nacional de governos em diferentes épocas, desde o Império, portanto reúne patrimônio, memória, identidade e bens que devem ser preservados. Segundo Lemos (1987, p. 85 apud SANTANA, 2011, p. 4), "o tombamento é um atributo que se dá ao bem cultural escolhido e separado dos demais para que, nele, fique assegurada a garantia de perpetuação da memória".

É relevante elucidar que o patrimônio enquanto instituição começa a existir em sua base legal no Brasil a partir de 30 de novembro de 1937, pelo então presidente Getúlio Vargas, o qual criou uma política para o Patrimônio Histórico e Artístico Nacional (SPHAN), atual Instituto do Patrimônio Histórico e Artístico Nacional (Iphan), a fim de proteger os bens móveis e imóveis do Brasil. Mário de Andrade, um dos intelectuais responsáveis pela legislação de patrimônio no país, ressaltava que esta política visava à construção da memória nacional. Mudanças nas políticas de patrimônio trouxeram novas perspectivas do que deveria ser preservado, o que resultou no Corredor Cultural do RJ. 


\section{Brazilian \\ Creative Industries}

Corredor Cultural. A Lei n 506, de Preservação Paisagística e Ambiental do Centro da Cidade do Rio de Janeiro, conhecida como a Lei do Corredor Cultural, foi aprovada em 17 de Janeiro de 1984 e depois revista e ampliada pela Lei n 1.139, de 16 de dezembro de 1987.

Iniciado como Projeto Corredor Cultural, ainda em 1979, foi uma iniciativa da prefeitura do Rio para proteger um importante acervo arquitetônico, histórico e ambiental do Centro da cidade, num contexto em que a maioria das pessoas pensava que a antiga capital não guardava mais nenhum patrimônio além do que já havia sido tombado pelos órgãos federal e estadual. Fonseca (2009) aborda outro motivo de criação do Corredor ao enfatizar que o Projeto ajudou a comerciantes e moradores locais que temiam as demolições ou renovações e queriam preservação do espaço ameaçado.

$\mathrm{Na}$ década de 70, naquele contexto de esvaziamento dos centros das cidades, iniciaram-se estudos em diversos países sobre como trazer as pessoas de volta aos centros. Augusto Ivan de Freitas Pinheiro (2002a), arquiteto, urbanista e coordenador do Projeto Corredor Cultural, além de ter sido um dos protagonistas na elaboração da política de preservação cultural do Centro do Rio, foi para a Holanda, em 1974, estudar e voltou interessado na questão da preservação e em conhecer uma nova maneira de lidar com a cidade. Pinheiro (2002b) pontua que a ideia do nome Corredor Cultural foi do então Superintendente de Planejamento da Prefeitura, Armando Mendes, que também contribuiu para a implantação do trabalho. "A explicação dele era simples: se existe a figura do corredor de tráfego, por que não poderia existir um corredor cultural?" (PINHEIRO, 2002b, p. 207).

Conforme o Decreto $n^{\circ} 4141$, de 14 de julho de 1983, Art. 3º o Corredor foi criado tendo em vista "o interesse de preservar e revitalizar áreas no Centro da Cidade levando em consideração os elementos ambientais que representam valores culturais, históricos, arquitetônicos e tradicionais para a população".

o Complexo Cultural da Marinha encontra-se na área abrangida pelo Corredor Cultural do centro do Rio, de acordo com o descrito no Decreto n 4141, de 14 de julho de 1983, Art. 3: "[...] seguindo por esta até o Cais Pharoux (todo incluído) [atual cais da Praça Quinze], seguindo por este até encontrar a linha de prolongamento da Avenida Presidente Vargas e por esta seguindo até o seu reinício".

Boulevard Olímpico. Desde a proposta pioneira de reestruturação do centro histórico do Rio de Janeiro com o Corredor Cultural até as iniciativas recentes para a região do Boulevard Olímpico com o Porto Maravilha, é claro o foco nos equipamentos culturais como vetores de desenvolvimento, conforme delineado por Pio (2014, p. 58-60) ao mostrar que, enquanto o Projeto Corredor Cultural se estrutura a partir da contenção de modernização para a preservação, vista como ameaça ao patrimônio da cidade, "a zona portuária é interpretada como 'novo vetor de crescimento' urbano. O patrimônio - histórico, paisagístico e cultural - é transformado em 'vocação do espaço'". 


\title{
Brazilian

\begin{abstract}
A transformação de um espaço abandonado e degradado em um cenário condizente com a beleza e a importância mundial da cidade do Rio. (...) Importante porta de entrada da cidade, o Porto do Rio passa agora de elemento coadjuvante no visual bonito da Baía de Guanabara para parte principal deste processo de construção de uma nova imagem do Rio. [...] A revitalização é vista, nesses discursos, como estratégia de desenvolvimento urbano e forma de estimular tanto o progresso social quanto a diversidade cultural. Essa diversidade é à base da dinâmica desses espaços e é vista como o ingrediente que valoriza o poder informador do patrimônio e dos centros históricos e a fruição estética - o que leva à visão do patrimônio como 'marca das cidades' ou 'instrumento de participação cívica'. [...] E 'a instalação do Museu do Amanhã no Píer Mauá confere força e charme ao projeto [...]'. (PIO, 2014, p. 57).
\end{abstract}

Nesse mesmo sentido observa-se que o Espaço Cultural da Marinha, fechado por dois anos, foi reaberto pouco antes dos Jogos Olímpicos, em agosto de 2016, e em 2017 foi lançado o projeto conceitual de um novo museu no mesmo Espaço - o Museu Marítimo (MuMa) - que contará com estudos para se adequar ao patrimônio histórico, naval e urbano do seu entorno:

O novo museu, localizado na orla histórica em frente à Igreja da Candelária e à antiga Alfândega do Rio de Janeiro (hoje a Casa França-Brasil), a meio caminho entre a Praça Mauá e a Praça XV, que depois da reforma estão interligadas por trajeto pedestre que margeia as águas da Baía de Guanabara, passará a constituir parte de um complexo de museus e centros culturais que já desloca para a região milhares de turistas, estudantes e consumidores de arte e cultura (MATHIAS, 2017, p. 9).

As palavras do Diretor de Patrimônio Histórico e Documentação da Marinha (DPHDM), reforçando o papel do futuro Museu, corroboram com o que os teóricos acentuam a respeito do papel da cultura para o desenvolvimento de cidades. Verifica-se que esses aparelhos culturais se tornam eixos de auxílio à reestruturação da zona portuária da cidade como pólo cultural.

No caso em foco, o argumento dos autores Landry $(1998,2000)$ e Reis $(2008,1012)$ se confirmam diante das iniciativas da Marinha no que tange à manutenção e criação de equipamentos culturais, que serão apresentados a seguir (além do já mencionado acima), pois esses se somam à atmosfera cultural/ criativa da cidade.

\subsubsection{Participação dos militares na economia criativa: Complexo Cultural do RJ}

A Marinha do Brasil é uma das Forças Armadas do Brasil destinada, entre outras missões, a contribuir com a "defesa da Pátria", conforme preconiza a Constituição Federal, no Art. n 142 (BRASIL, 


\section{Brazilian

1988). Ao comparar a etimologia de "Pátria" e "Patrimônio" (SILVA, 2003), ambas originadas do vocábulo latim pater (pai) - no sentido que pontua Santana (2011, p. 4), "o Patrimônio [...] já demonstrava desde a antiguidade sua relação com a ideia de Pátria". Visualiza-se aqui, não por acaso, o papel da Marinha em preservar e valorizar a tradição, o patrimônio cultural e histórico e os seus bens culturais.

A proposta dos aparelhos culturais da Marinha no Corredor Cultural é a de um embarque pela história do Brasil e da navegação. Nesse sentido de resgate da memória e valorização do patrimônio histórico, Chauí (2005, p. 138) retrata que "memória é uma evocação do passado. É a capacidade humana para reter e guardar o tempo que se foi, salvando-o da perda total. A lembrança conserva aquilo que se foi e não retornará jamais". De acordo com o gerente de visitação do Complexo Cultural da Marinha no RJ, Capitão de Fragata RM1 (T) José Marques da Silva Filho, "mais que equipamentos culturais da Marinha, eles são a materialização da história". (SILVA FILHO, 2019, informação oral²).

Além disso, o Complexo Cultural da Marinha no Rio "compõe o pólo cultural da Praça XV, juntamente com outros museus da região" (SILVA FILHO, 2019, informação oral³). Corresponde aos seguintes equipamentos culturais: o Museu Naval, onde funciona a sede da DPHDM - que é a Organização Militar da Marinha responsável pelo Complexo -; o Espaço Cultural, que abrange os passeios marítimos (Baía de Guanabara e Ilha Fiscal), a Nau dos Descobrimentos, o Helicóptero Sea King, o Submarino "Riachuelo", o Contratorpedeiro "Bauru" e o carro de combate Cascavel; além da Ilha Fiscal (DPHDM, 2019).

Ilha Fiscal. Ilha dos Ratos era o seu nome até 1882, passando a ser chamada de Ilha Fiscal após a construção do posto de fiscalização alfandegária. Foi transferida para a Marinha pelo Ministério da Fazenda, em 1913, e hoje é parte do Complexo Cultural. Cenário do último Baile do Império, realizado alguns dias antes da Proclamação da República, em 1889 (SEC-RJ, 2013). 0 castelo aberto à visitação tem como destaques: o Torreão, com o relógio alemão de quatro faces, o piso em mosaico feito com 14 tipos de madeiras nobres brasileiras; a sala do cerimonial, com os talheres na mesa de jantar que pertenceram ao Encouraçado São Paulo - navio que participou das duas guerras mundiais -, entre outras raridades.

Ela ocupa uma área de 7000 m2 e se distancia do continente pouco mais de 1 km. O "castelinho" (DPHDM, 2019), que testemunhou tantos fatos históricos, é hoje instrumento turístico da cidade ao continuar sendo um elo com a história. A ilha abriga ainda exposições, as quais mostram a participação da Marinha do Brasil no desenvolvimento econômico e social do País.

2 SILVA FILHO, J. M. Entrevista à autora por telefone em 14/6/2019

3 SILVA FILHO, J. M. Entrevista à autora por telefone em 14/6/2019. 


\section{Brazilian \\ Creative Industries}

Museu Naval. Conta com a exposição permanente "O Poder Naval na Formação do Brasil" e a importância da Marinha para consolidar a unidade nacional. Retrata desde a chegada dos portugueses, as diversas invasões vindas pelo mar, o período de colonização, o período da chegada da família Real no Brasil, a Regência, o Império e a República até os dias de hoje. "Um passeio pela Memória da Marinha do Brasil." (DPHDM, 2019). As sete salas do andar térreo são ocupadas por uma exposição permanente onde estão expostas maquetes navais e canhões resgatados de navios naufragados. No vão central do Pátio d'Armas destaca-se o móbile "Aves dos Mares do Brasil", formado por 52 aves representativas das 12 espécies que sobrevoam os mares do Brasil. No chão, o visitante pode observar uma mina utilizada na Segunda Guerra Mundial e um torpedo B-57 de 1894. O Museu Naval está situado em um prédio construído em 1868.

Espaço Cultural. Foi criado em 20 de janeiro de 1996, nas antigas Docas da Alfândega do Porto do Rio de Janeiro, após uma grande reforma em sua estrutura. É de onde partem os passeios, um pela Baía de Guanabara e o outro para a llha Fiscal. É nele que estão reunidos os Museus de exemplares dos meios operativos da Marinha (submarino, navio, helicóptero e carro de combate, conforme detalhamento abaixo).

Carro de combate Cascavel. No Espaço também está disponível para visita o carro anfíbio de combate, atração tanto para crianças quanto para adultos, que percorrem o veículo para experimentar um pouco do que os Fuzileiros Navais fazem.

Helicóptero-Museu SH-3 Sea King. Já pertenceu à frota de aeronaves da Marinha na década de 70, cumpriu missões de busca e combate contra submarinos e navios. O Sea King era equipado com radar e sonar, além de ser armado com torpedos e com o míssil antinavio. Ele faz parte de uma frota de aeronaves que já operou a bordo dos porta-aviões Minas Gerais e São Paulo.

Nau dos Descobrimentos. Um modelo em escala aproximada de uma nau. Ela retrata uma exposição sobre a vida a bordo na época dos descobrimentos.

Submarino-Museu Riachuelo. Foi incorporado à Armada brasileira em 1977. Sétimo navio da Marinha do Brasil a ostentar este nome, homenagem à batalha naval de 11 de junho de 1865 entre a esquadra paraguaia e uma fração da esquadra brasileira, sob o comando do Almirante Barroso. Após 20 anos em operação foi desincorporado do Serviço Ativo da Armada em 1997, sendo reclassificado como Submarino-Museu.

Navio-Museu Bauru. Foi construído nos EUA e incorporado à Marinha americana em 1943. Prestou serviços àquela Marinha até 1944, quando foi transferido para a Marinha do Brasil, recebendo o nome de Bauru em homenagem à cidade paulista de Bauru. Durante a Segunda Guerra Mundial, o Contratorpedeiro-Escolta Bauru participou de comboios e efetuou missões de apoio no transporte de 


\title{
Brazilian

tropas e patrulhamento em zonas de guerra. Após sofrer reformas de adaptação, foi aberto à visitação pública em 1982 como navio-museu.

Museu Marítimo (em fase de captação de recursos para construção). Previsto para 2022, o Museu Marítimo do Brasil será construído no Espaço Cultural da Marinha. "O estudo arquitetônico propõe uma integração mais efetiva com os outros pontos culturais localizados na região" (DPHDM, 2017). O MuMar pretende ter exposições permanentes e temporárias relacionadas à História Marítima Brasileira, "seu passado, presente e perspectivas futuras" (DPHDM, 2017).

\subsubsection{A interação da Marinha com a sociedade civil}

O Complexo Cultural da Marinha é um espaço raro, que, além de contar a história do Brasil e da Marinha, mostra os meios operativos nos quais os marinheiros trabalham: aéreo, de superfície, submerso e os de terra - resumem um pouco do que a Marinha faz.

\begin{abstract}
Isso tudo faz com que os visitantes e os que transitam pela região sejam atraídos pela curiosidade em conhecer os meios navais, tenham maior contato com a memória e o patrimônio cultural da Força. "São oportunidades da Marinha se aproximar do cidadão e se posicionar diante da sociedade (SILVA FILHO, 2019, informação oral4).
\end{abstract}

A abordagem dos aparelhos culturais abrange vários perfis de visitantes. Os que gostam de história serão aqueles que procurarão os navios-museus: rebocador Laurindo Pitta, que participou da primeira Guerra Mundial, ou o antigo Contra-Torpedeiro Bauru, que testemunhou a Segunda Guerra, ou ainda a Nau dos Descobrimentos, "para desvendar como Cabral chegou ao Brasil" (SILVA FILHO, 2019, informação oral5). Existem também os visitantes que são atraídos pelas atividades militares, os quais vão buscar viver a experiência de embarcar no submarino-museu Riachuelo ou no Helicóptero Sea King, e ainda visitar o carro de combate Cascavel. "Em geral, todos que vão ao local experimentam uma amostra do trabalho diário feito pela Marinha" (SILVA FILHO, 2019, informação oral')

O valor simbólico do Complexo e a sua importância para o aumento da interação entre a sociedade e a Marinha foi destacada pelo Comandante Marques (2019): "É o único no país com a característica de

\footnotetext{
${ }^{4}$ SILVA FILHO, J.M. Entrevista às autoras por telefone em 14/6/2019.

5 SILVA FILHO, J.M. Entrevista às autoras por telefone em 14/6/2019.

${ }_{6}^{6}$ SILVA FILHO, J.M. Entrevista às autoras por telefone em 14/6/2019.
} 


\section{Brazilian

interligar a cultura e a interatividade e cumprir a missão de preservar o patrimônio cultural, resgatar a história e auxiliar o desenvolvimento da região" (SILVA FILHO, 2019, informação oral).

Esse papel cultural que a Marinha cumpre reflete a imagem que a sociedade tem da Força Armada em lide. Pesquisa de opinião realizada pela Fundação Getúlio Vargas (FGV) em 2014 constatou que entre as atividades específicas da Força listadas na pesquisa, as relacionadas à cultura somaram 12\% - o maior índice - em relação aos serviços conhecidos pela população. A pesquisa foi encomendada pelo Centro de Comunicação Social da Marinha e teve o objetivo de avaliar a imagem da MB perante a sociedade brasileira (MARINHA DO BRASIL, 2016).

O Complexo da Marinha recebeu no último ano 154 mil visitantes. Somente a llha Fiscal soma 34 mil visitas, e os passeios marítimos reuniram 35.920 pessoas (DPHM, 2019). O gerente do Complexo pontua ainda que o preço das visitas é calculado para ser de baixo custo a fim de abranger o maior número possível de pessoas, com valores acessíveis. Os alunos de escolas públicas pagam um valor diferenciado em relação aos outros estudantes e às terças-feiras a entrada é gratuita. "A Marinha tenta contribuir para a formação cultural dos alunos, criando incentivos e programas de visitas personalizados para eles". Nesse sentido, a Diretoria do Patrimônio Histórico da Marinha realiza, desde 1998, o Projeto Escola, com visitas guiadas aos aparelhos culturais do local.

Além dessas, foram constatadas uma série de ações esporádicas a fim de aproximar a sociedade por meios dos atrativos culturais. Para citar como exemplo, a DPHDM realizou em 15 de junho de 2019 um dia de programação criativa e cultural voltada para todos os públicos, com destaque para o infantil, em homenagem a uma data tradicional da Marinha, 11 de junho, em memória à Batalha Naval do Ricahuelo DPHDM (2019). Nesse sentido, o Espaço Cultural da Marinha promoveu: jogos infantis com alusão a temas navais; apresentações da banda de música do Corpo de Fuzileiros Navais (CFN); circuito expositivo sobre atividades esportivas, com o Centro de Educação Física Almirante Adalberto Nunes (CEFAN); experiência de imersão em ações do Grupamento de Mergulhadores de Combate (GRUMEC), por meio dos óculos de visão noturna; exposição de meios navais pela Capitania dos Portos do Rio de Janeiro (CPRJ), como moto aquática; Biblioteca Volante, com o "Cantinho da Leitura"; entre outras atrações, além das atrações costumeiras do Espaço.

\footnotetext{
7 SILVA FILHO, J.M. Entrevista às autoras por telefone em 14/6/2019.
} 


\section{Brazilian

\section{CONSIDERAÇÕES FINAIS}

Ações de demonstração da tradição militar, ao mesmo tempo em que bens culturais marinheiros são difundidos e mais acessíveis a um número cada vez maior de visitantes, permitem com que a sociedade conheça o papel da Força Armada no País.

Portanto, nessa perspectiva, é possivel observar que o argumento central deste artigo foi corroborado totalmente. Os aparelhos culturais contribuem com a relação da Marinha do Brasil e a sociedade na área do Corredor Cultural do Rio de Janeiro. Além disso, o Complexo auxilia na manutenção de cidadãos naquela região, com possibilidade de viver as experiências no passeio marítimo e se reconectar com o mar, ou embarcar pela história do país na Ilha Fiscal, ou nas embarcações utilizadas pela Marinha ao longo de sua história, acessiveis a todos os públicos.

O retorno das conexões da população carioca com o mar, destacado em obra publicada pela Unesco (RIBEIRO, 2016), nesse espaço da cidade criativa que se reconfigura na região, marcado pelo lazer, diante da paisagem marítima, moldado pela história e pelo patrimônio cultural, é uma atmosfera que merece ser tombada, como já dizia Maria de Andrade, e vem permeado de potencial a ser explorado pelo Complexo no campo da Comunicação Institucional. Essa é uma das temáticas pontuadas para desenvolvimentos de estudos posteriores, a fim de aprofundar a análise sobre Economia Criativa na mesma perspectiva. Por meio de pesquisas futuras, será notório analisar se é realizada Comunicação Pública no Complexo, além de verificar as estratégias de Comunicação Institucional utilizadas, com o viés da Economia Criativa.

Esses desdobramentos justificam-se ao encontrar nesse público antes distante daquela região central da cidade uma oportunidade de potencializar a divulgação da história naval brasileira, de fomentar a mentalidade marítima, ou, em outras palavras, de comunicar aos brasileiros o que a Marinha tem a mostrar - e se mostrar - por meio do patrimônio.

Conclui-se que os patrimônios culturais e históricos abordados neste artigo estão incluídos na economia criativa por se tratarem de valores simbólicos intangíveis de um povo, melhor dizendo, de uma nação.

O Complexo Cultural da Marinha preserva, valoriza e difunde o patrimônio histórico tanto da Força Armada quanto do Brasil, estímulo esse fornecido à Economia Criativa na cidade carioca, e, por consequência, ao desenvolvimento da região. "A economia criativa tem o poder de influenciar e inspirar as gerações presentes e futuras, proteger nosso planeta, pessoas, culturas e recursos naturais e, portanto, contribuir para um caminho de desenvolvimento mais sustentável." (UNESCO, 2019). 


\section{Brazilian Creative Industries}

\section{REFERÊNCIAS}

ABREU, R.; CHAGAS, M. Introdução. In: ABREU, R.; CHAGAS, M. (orgs.) Memória e patrimônio: ensaios contemporâneos. Rio de Janeiro: Lamparina, 2009.

BOKOVA, Irina. Textos base. In: Convenção de 2003 para a Salvaguarda do Patrimônio Cultural Imaterial. Paris: Unesco, 2012. Diponivel em: https://docs.wixstatic.com/ugd/588860_c392e4a2bab84c8da21a48ffeOf2afb3.pdf. Acesso em: 11 set. 2019.

CHAUII, M. Convite à filosofia. 13 ed. São Paulo: Ática. 2005.

FIGUEIREDO, J. L. de; JESUS, D. S. V. de (Org.). Cidades criativas: aspectos setoriais e territoriais. Rio de Janeiro: E-papers, 2017.

FIRJAN. Mapeamento da indústria criativa no Brasil. Rio de Janeiro: Firjan, 2019.

FONSECA, T. P. da. Participação em ações de preservação: o caso do Corredor Cultural do Rio de Janeiro. Risco, v. 10. 2009, p. 35-44. Disponivel em: http://www.revistas.usp.br/risco/article/ view/44778/48409. Acesso em: 30 mai. 2019.

GONÇALVES, J. R. S. Monumentalidade e cotidiano: os patrimônios culturais como gênero de discurso. In: OLIVEIRA, Lúcia Lippi (Org.). Cidade: história e desafios. Rio de Janeiro: Editora FGV, 2002.

HARTOG, François. Tempo e patrimônio. Varia Historia, Belo Horizonte, PPGHis-UFMG, v. 22, n. 36, jul./ dez. 2006, p. 261-273.

HALBWACHS, Maurice. A memória coletiva. São Paulo: Editora Revista dos Tribunais, 1990.

JESUS, D. S. V. de. Saudade de mim: patrimônio cultural e economia criativa na cidade do Rio de Janeiro. In: FIGUEIREDO, J. L. de; JESUS, D. S. V. de (Org.). Cidades criativas: aspectos setoriais e territoriais. Rio de Janeiro: E-papers, 2017.

KITUYI, M. Creative Economy Outlook: Trends in international trade in creative industries. In: UNCTAD - United Nations Conference on Trade and Development. Disponível em: https://unctad.org/en/PublicationsLibrary/ditcted2018d3_en.pdf. Acesso em: 09 jun. 2019.

LANDRY, C. Prefácio. In: REIS, Ana Carla Fonseca; KAGEYAMA, P. (Orgs.). Cidades criativas: perspectivas. São Paulo: Garimpo de Soluções, 2011. p. 7-15.

LANDRY, C. The creative city: a toolkit for urban innovators. Londres: Earthscan, 2000. 


\section{Brazilian Creative Industries}

LANDRY, C.; BIANCHINI, F. The creative city. Reino Unido: Demos, 1998. E-book. Disponivel em: https:// www.demos.co.uk/files/thecreativecity.pdf. Acesso em: 20 maio 2019.

MACHADO, Sandra. Corredor Cultural preserva memória do Rio. Multirio, Rio de Janeiro, 06 jan. 2015. Disponivel em: http://www.multirio.rj.gov.br/index.php/leia/reportagens-artigos/reportagens/993-mapa. Aceso em: 27 maio 2019.

MADEIRA, M. G. Economia criativa: implicações e desafios para a política externa brasileira. Brasília: FUNAG, 2014.

MATHAIS, J. C. Museu Marítimo - MuMa. Revista Marítima Brasileira, Rio de Janeiro, v. 138, n. 04/06, p. 8-10, abr./jun., 2017. Disponível em: http:/www.revistamaritima.com.br/revistas/museu-maritimo. Acesso em: 01 jun. 2019.

MUSEUS NAVAIS. DPHDM. Disponível em: https://www.marinha.mil.br/dphdm. Acesso em: 01 jun. 2019. NORA, Pierre. Entre memória e história: a problemática dos lugares. Projeto História, São Paulo, PUC$-S P$, n. 10, 1993, p. 7-28.

OLIVEIRA, L. L. (Org). Cidade: história e desafios. Rio de Janeiro: Ed. Fundação Getulio Vargas, 2002.

SILVA, De P. e. Vocabulário jurídico. Pátria. 23 ed. Rio de Janeiro: Forense, 2003, p. 1014.

SILVA, De P. e. Vocabulário jurídico. Patrimônio. 23 ed. Rio de Janeiro: Forense, 2003, p. 1014.

PINHEIRO, A. I. de F. Aprendendo com o Patrimônio. In: OLIVEIRA, Lúcia Lippi (org). Cidade: história e desafios. Rio de Janeiro: Ed. Fundação Getulio Vargas, 2002a.

PINHEIRO, A. I. de F. Novas Experiências em urbanismo: Barra da Tijuca e Corredor Cultural. In: FREIRE, Américo; OLIVEIRA, Lúcia Lippi (org). Capítulos da memória do urbanismo carioca: depoimentos ao CPDOC/ FGV. Rio de Janeiro: Folha Seca, 2002 b.

PIO, L. G. Cidade e Patrimônio nos projetos Corredor Cultural e Porto Maravilha. Revista Húmus, v. 4, n. 10, 2014, p. 55-65. Disponivel em: http:/www.periodicoseletronicos.ufma.br/index.php/revistahumus/ article/view/2360. Acesso em: 19 maio 2019.

REIS, A. C. F. Cidades Criativas: da teoria à prática. São Paulo: SESI-SP editora, 2012.

REIS, A. C. F. Economia Criativa como estratégia de desenvolvimento: uma visão dos países em desenvolvimento. São Paulo: Garimpo de Soluções e Itaú Cultural, 2008. 


\section{Brazilian Creative Industries}

REIS, A. C. F. Economia da cultura e desenvolvimento sustentável: O caleidoscópio da cultura. Barueri: Manole, 2005.

REIS, A. C. F.; KAGEYAMA, P. (Org.). Cidades Criativas-Perspectivas. São Paulo: Garimpo de soluções \& Creative Cities Productions, 2011.

RIBEIRO, R. W. Rio de Janeiro: paisagens cariocas entre a montanha e o mar. São Paulo: Editora Brasileira de Arte e Cultura; Brasilia: UNESCO, 2016. Disponivel em: https://unesdoc.unesco.org/ark:/48223/ pf0000246757. Acesso em: 08 jun. 2019.

RIO DE JANEIRO. Lei $\mathbf{n}^{\circ} . \mathbf{5 0 6}$ de $\mathbf{1 7}$ de janeiro de 1984. Disponivel em: http://wwwO.rio.rj.gov.br/patrimonio/apac/. Acesso em: 16 maio 2019.

RIO DE JANEIRO. Decreto n. 4141 de $\mathbf{1 4}$ de julho de 1983. Disponivel em: http://www0.rio.rj.gov.br/patrimonio/pastas/legislacao/centro_dec4141_83_corredor_cultural.pdf. Acesso em: 16 maio 2019.

ROLIM, Eliana de Souza. Patrimônio histórico, memória, história e construção de saberes. In: XXVII Simpósio Nacional de História. Natal, 22 a 26 de julho de 2013. Anais... São Paulo: Anpuh, 2013. Disponível em: www.snh2013.anpuh.org/resources/anais/27/1371265630_ARQUIVO_ArtigoXXVIISimposioNacionalversaofinal.pdf. Acesso em: 02 jun. 2019.

SANTA CRUZ, L. O Amanhã no Museu. In: FIGUEIREDO, J. L. de; JESUS, D. S. Vieira de (Org.). Cidades criativas: aspectos setoriais e territoriais. Rio de Janeiro: E-papers, 2017.

SANTANA, N. M. C. de. Memória, Políticas de Patrimônio e Turismo: o Corredor Cultural no Rio de Janeiro. In: XXVI Simpósio Nacional de História. São Paulo, 17 a 22 de julho de 2011. Anais... São Paulo: Anpuh, jul. 2011. Disponivel em: http://www.snh2011.anpuh.org/resources/anais/14/1308182702_ARQUIVO_TextoANPUH.pdf. Acesso em: 02 jun. 2019.

SECRETARIA DE ESTADO DE CULTURA DO RIO DE JANEIRO (SEC-RJ). Complexo Cultural da Marinha. Museus do Rio - Um guia de memórias e afetividades. Rio de Janeiro, 2013. Disponível em: https://www. museusdorio.com.br/joomla/index.php?option=com_k2\&view=item\&id=52:complexo-cultural-da-marinha-espa\%C3\%A7o-cultural-da-marinha. Acesso em: 01 jun. 2019.

SECRETARIA DE ESTADO DE CULTURA DO RIO DE JANEIRO. Complexo Cultural da Marinha. Museus do Rio - Um guia de memórias e afetividades. Rio de Janeiro, 2013. Disponivel em: https://www.museusdorio.com.br/joomla/index.php?option=com_k2\&view=item\&id=52:complexo-cultural-da-marinha-espa\%C3\%A7o-cultural-da-marinha. Acesso em: 01 jun. 2019. 


\section{Brazilian Creative Industries}

SILVA FILHO, J. M. Complexo Cultural da Marinha - gerente de visitação. Entrevista à autora, via telefone, em 14 jun. 2019.

THROSBY, D. Economics of cultural politics. Cambridge: University Press: 2010.

UNCTAD. Creative Economy Outlook: Trends in international trade in creative industries. Disponivel em: https://unctad.org/en/PublicationsLibrary/ditcted2018d3_en.pdf. Acesso em: 09 jun. 2019.

UNESCO. Cultura e desenvolvimento sustentável. Disponível em: http://www.unesco.org/new/pt/brasilia/culture/culture-and-development/culture-in-sustainable-development/. Acesso em: 08 jun. 2019. 